\title{
Rescue therapy with inhaled nitric oxide in criti- cally ill patients with severe hypoxemic respiratory failure (Brief report)
}

\author{
[Thérapie de secours par l'inhalation d'oxyde nitrique chez de grands malades \\ atteints d'insuffisance respiratoire hypoxémique]
}

Fred J. Baxter MD FRCPC, ${ }^{\star} \$$ Jill Randall BA RRT RRCP, $\ddagger$ John D. Miller MD FRCSC, $\mathbb{I}$ David A. Higgins MB FRCPC, $\dagger$ A.C. Peter Powles MB CHB FRCPC, $\uparrow \$$ Peter T.-L. Choi MD FRCPC MSc*

Purpose: To evaluate the efficacy of inhaled nitric oxide (iNO) on oxygenation, shunt, and pulmonary vascular resistance index (PVRI) in severely hypoxemic, ventilated patients.

Methods: In a two-period double-blind crossover design, 14 critically ill, hypoxemic, ventilated patients were randomized to receive iNO 10 ppm in 100\% oxygen or no iNO in 100\% oxygen for 30 min followed by a 30-min washout period and then crossed over to the other intervention. Responders to iNO then received iNO, which was increased from $5 \mathrm{ppm}$ to $25 \mathrm{ppm}$ in $5 \mathrm{ppm}$ increments. Severity of illness scores and cardiorespiratory variables were measured.

Results: Nitric oxide decreased shunt $(P=0.002)$ and PVRI $(P=0.033)$ and increased oxygenation $(P=0.01 \mathrm{I})$ although the lat ter two were not statistically significant after adjustment for multiple comparisons. Treatment by period interactions were observed.

Conclusion: Our findings suggest that iNO improves oxygenation to a clinically significant extent in critically ill patients who are severely hypoxemic.

Objectif : Évaluer l'efficacité de l'inhalation d'oxyde nitrique (iNO) sur l'oxygénation, le shunt et l'index de résistance vasculaire pulmonaire (IRVP) chez des sujets atteints d'hypoxémie sévère et placés sous ventilation.

Méthode : Une étude de type croisée, à double insu et en deux temps a été réalisée auprès de 14 grands malades hypoxémiques placés sous ventilation. On les a répartis au hasard pour recevoir 10 ppm de iNO dans 100 \% d'oxygène ou 100 \% d'oxygène sans iNO pendant 30 min suivies d'une élimination de 30 min et de la permutation des interventions. Les sujets répondants à l'iNO ont alors reçu de l'iNO qui a été augmenté de 5 ppm à 25 ppm par paliers de 5 ppm. La sévérité de la maladie et des variables cardio-respiratoires a été mesurée.

Résultats : L'oxyde nitrique a réduit le shunt $(P=0,002)$ et l'IRVP $(P=0,033)$ et augmenté l'oxygénation $(P=0,011)$ bien que ces deux dernières modifications n'étaient pas statistiquement significatives à la suite d'un ajustement pour comparaisons multiples. Le traitement par période d'interactions a été étudié.

Conclusion : Nos résultats indiquent que l'iNO améliore l'oxygénation clinique de façon significative chez les grands malades souffrant d'hypoxémie sévère.

I NHALED nitric oxide (iNO) acutely improves oxygenation and decreases pulmonary artery pressure (PAP) in patients with severe acute respiratory distress syndrome (ARDS) but improvement in arterial oxygen tension $\left(\mathrm{PaO}_{2}\right)$ may not be beyond $24 \mathrm{hr}^{\mathrm{l}-3}$ and survival in ARDS patients may be unchanged. ${ }^{2-5}$ In this report, we present the results of a blinded study designed to assess the efficacy of iNO $10 \mathrm{ppm}$ on oxygenation, shunt, and pulmonary vascular resistance in severely hypoxemic, ventilated patients and to determine the optimal dose, in terms of improvement in $\mathrm{PaO}_{2}$, to five doses of iNO.

Methods

This study was approved by our Ethics Review Board. Eligibility criteria were age greater than $15 \mathrm{yr}$,

From the Departments of Anaesthesia, ${ }^{\star}$ Medicine, $\dagger$ and Respiratory Therapy, $\ddagger$ and the Divisions of Critical Care Medicine, $\$ \$$ and Thoracic Surgery, I St. Joseph's Healthcare and McMaster University, Hamilton, Ontario, Canada.

Address correspondence to: Dr. Fred Baxter, Department of Anaesthesia, St. Joseph's Hospital, 50 Charlton Avenue East, Hamilton,

Ontario L8N 4A6, Canada. Phone: 905-522-4941 (ext. 3853); Fax: 905-521-6019; E-mail: barbroszel@hotmail.com

Presented in part at the $12^{\text {th }}$ World Congress of Anaesthesiology, Montréal, Québec, Canada.

Accepted for publication February 15, 2001.

Revision accepted November 5, 2001. 


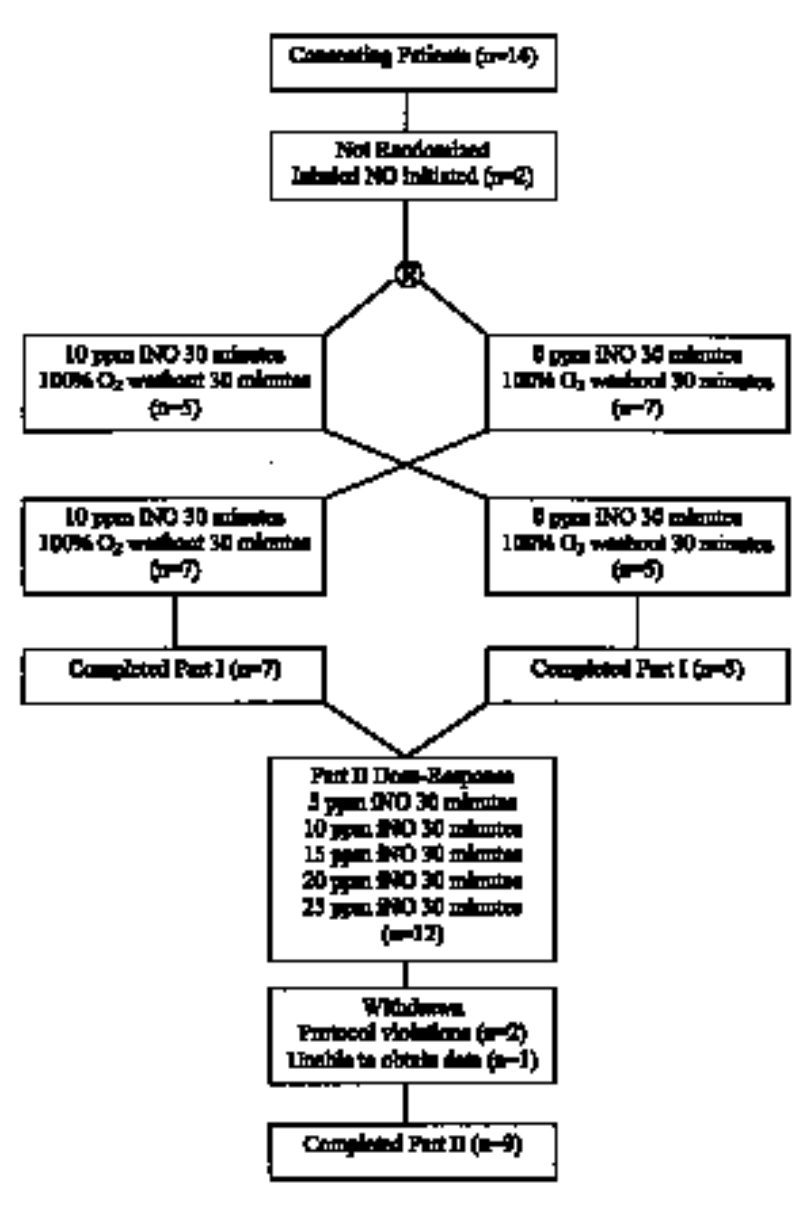

FIGURE 1 Flow diagram of the various stages of this trial. The " $\mathrm{R}$ " indicates randomization.

$\mathrm{PaO}_{2} \cdot \mathrm{FIO}_{2}^{-1}$ ratio $<200$ despite mechanical ventilation with $100 \%$ oxygen, and a mean PAP greater than 20 $\mathrm{mmHg}$. Exclusion criteria were pregnancy, sustained hemodynamic instability, moribund state, history of prior home oxygen use, liver cirrhosis, known intracardiac shunt, or an absolute contraindication to anticoagulation. Written informed consent was obtained from the next-of-kin.

All patients were ventilated with a Puritan-Bennett 7200 ventilator with NO $800 \mathrm{ppm}$ in nitrogen introduced through the ventilator air intake after further blending with nitrogen or air. A Pulmonox II electrochemical monitor in the inspiratory limb continuously monitored iNO and $\mathrm{NO}_{2}$.

The study consisted of a two-period crossover trial and a dose-finding study. All patients remained on $100 \%$ oxygen during the entire study. Aside from the respiratory therapist who applied the study interven-

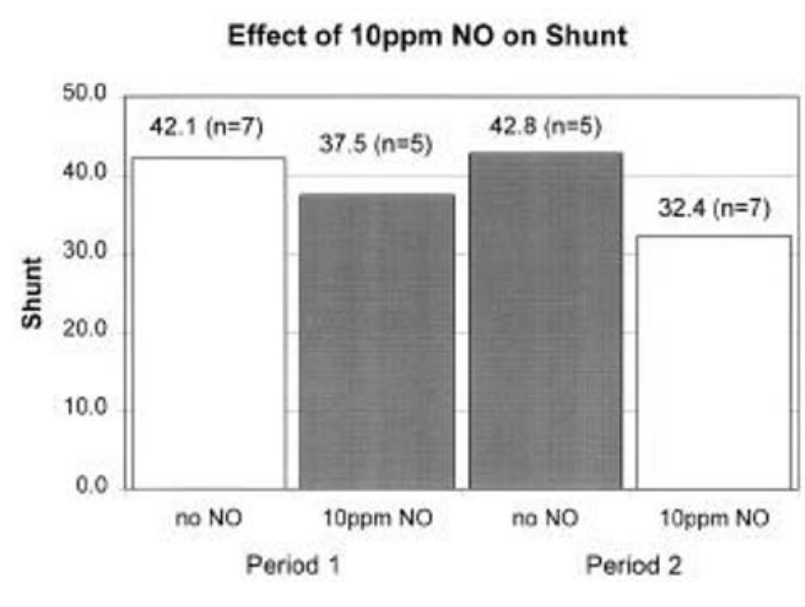

FIGURE 2 Bar graph of the effect of inhaled nitric oxide (iNO) 10 ppm on cardiac shunt. The dark bars denote Group A (iNO then no iNO); the white bars denote Group B (no iNO then iNO). The mean value for each group by period and intervention is listed above the respective bar.

tion, patients, caregivers, and trial participants were blinded.

Using computer generated random numbers, we randomized patients to receive either iNO $10 \mathrm{ppm}$ for $30 \mathrm{~min}$ followed by a 30 -min washout period on $100 \%$ oxygen without iNO (group A) or 100\% oxygen without iNO for $30 \mathrm{~min}$ followed by a second 30 -min period on 100\% oxygen (group B). Patients then crossed over to the alternate intervention for $30 \mathrm{~min}$ followed by a 30 -min washout period on $100 \%$ oxygen. We defined a positive response as a $10 \mathrm{mmHg}$ increase in $\mathrm{PaO}_{2}$. Patients with positive responses then received iNO 5 ppm $30 \mathrm{~min}$ followed by $5 \mathrm{ppm}$ increases after each 30-min period until a final dose of $25 \mathrm{ppm}$ was attained (Figure 1).

We measured the following variables at the end of each period: $\mathrm{PaO}_{2}$, venous oxygen tension, arterial and venous oxygen saturation, hemoglobin level, systolic, diastolic and mean arterial pressures, pulmonary artery occlusion pressure, and cardiac output. Oxygenation index $\left(\mathrm{PaO}_{2} \cdot \mathrm{FIO}_{2}{ }^{-1}\right)$, cardiac shunt $\left(\mathrm{Qs} \cdot \mathrm{Qt}^{-1}\right)$, cardiac index, PVRI, and systemic vascular resistance index (SVRI) were calculated.

For the first part of this study, the data for each group were summarized by period due to the crossover design. Treatment by period interactions (residual effects from crossover) were analyzed as described by Willan and Pater., ${ }^{6,7}$ In the absence of period effects and treatment interactions, data from both groups were pooled by intervention (no iNO, 10 
ppm iNO); two-sided paired $t$ tests were used for comparisons. In the presence of treatment by period interactions, modified paired t tests were used for comparisons. Linear regression was used to examine for the presence or absence of a dose-response in the second part of this study. Bonferroni correction for multiple comparisons was used. A $P$-value $<0.01$ was considered to be significant.

Results

Fourteen ventilated patients with severe hypoxemia were enrolled in the study but two patients were started on $10 \mathrm{ppm}$ iNO before randomization occurred due to the severity of their hypoxemia; they were excluded from the analysis. The Table highlights patient characteristics by group at time of randomization.

Two patients received assist-control ventilation; ten patients received pressure control inverse ratio ventilation at the time of randomization. Mean positive endexpiratory pressure was $6.9 \pm 3.2 \mathrm{~cm} \mathrm{H}_{2} \mathrm{O}$. Mean PVRI was $560.1 \pm 178.9$ dyne $\cdot \mathrm{sec}^{-1} \cdot \mathrm{cm}^{-5} \cdot \mathrm{m}^{2}$. Responders received iNO for four to 29 days.

Figure 2 summarizes the effect of iNO $10 \mathrm{ppm}$ on $\mathrm{PaO}_{2} \cdot \mathrm{FIO}_{2}{ }^{-1}$ Treatment by period interactions were found; therefore, the data have been summarized separately for each group. All twelve randomized patients responded to iNO $10 \mathrm{ppm}$, which decreased $\mathrm{Qs} \cdot \mathrm{Qt}^{-1}$ $(P=0.002)$ and PVRI $(P=0.033)$ and increased $\mathrm{PaO}_{2} \cdot \mathrm{FIO}_{2}{ }^{-1} \quad(P=0.011)$. No adverse hemodynamic effects were noted.

Nine of the 12 responders completed the dosefinding study. Maximal increase in $\mathrm{PaO}_{2}$ was found at $5 \mathrm{ppm}$ in five patients, $10 \mathrm{ppm}$ in two patients, 15 ppm in one patient and $20 \mathrm{ppm}$ in one patient.

For all patients, $\mathrm{NO}_{2}$ levels remained below $2 \mathrm{ppm}$. Methemoglobin levels did not exceed 1.6\%. No acute hemorrhage occurred during iNO administration.

Discussion

Our intention was to assess the utility of iNO in critically ill hypoxemic patients. NO was reserved for rescue therapy after other options commonly used in our practice had failed to improve oxygenation to a satisfactory level.

Because we planned to study a severely ill subset of critically ill patients and anticipated a small number of participants, we deliberately chose a two-period crossover design to permit all study participants an opportunity to receive iNO. In the absence of treatment by period interactions, the crossover trial compares interventions within each patient, minimizes between-subject variability, and results in an increased power with a reduced sample size. ${ }^{6}$ In the presence of interactions,
TABLE Description of patients at time of enrollment

\begin{tabular}{lll}
\hline Patient characteristic & Group $A(n=5)$ & Group $B(n=7)$ \\
\hline Age $(\mathrm{yr})$ & $71.2 \pm 5.2$ & $58.7 \pm 14.9$ \\
APACHE II score & $29.2 \pm 2.5$ & $24.9 \pm 6.5$ \\
$\mathrm{LIS}$ & $3.10 \pm 0.31$ & $2.64 \pm 0.45$ \\
$\mathrm{PaO} \cdot \mathrm{FIO}_{2}^{-1}$ & $57.4 \pm 8.4$ & $64.4 \pm 9.5$ \\
$\mathrm{PEEP}\left(\mathrm{cm} \mathrm{H}_{2} \mathrm{O}\right)$ & $8.5 \pm 2.2$ & $5.7 \pm 3.4$ \\
PVRI $\left(\right.$ dyne $\left.\cdot \mathrm{sec}^{-1} \cdot \mathrm{cm}^{-5} \cdot \mathrm{m}^{2}\right)$ & $450.6 \pm 61.1$ & $638.3 \pm 197.6$ \\
\hline
\end{tabular}

APACHE=acute physiology and chronic health evaluation; LIS=lung injury score; $\mathrm{PEEP}=$ positive end-expiratory pressure; PVRI=pulmonary vascular resistance index. All values are expressed as means \pm standard deviations.

first period data may still be used to draw inferences. Modified paired $t$ tests may be used to make comparisons between interventions using data from both periods. ${ }^{7}$

Our patients had a mean $\mathrm{PaO}_{2} \cdot \mathrm{FIO}_{2}{ }^{-1}$ of 61.5 before study entry, with a mean APACHE II score of 26.6, making this one of the most compromised groups yet studied. Mortality was $20 \%$, which is comparable with recent ARDS mortality data. ${ }^{8}$ The majority $(10 / 12,83 \%)$ of these patients responded with a clinically significant increase in $\mathrm{PaO}_{2}$. This increase corroborates the findings of other investigators that iNO produces an acute increase in $\mathrm{PaO}_{2}$ in most patients with severe hypoxemic respiratory failure. ${ }^{9,10}$ Current evidence suggests that the beneficial effects of iNO in terms of improvement in $\mathrm{PaO}_{2}$ may last only 24 to $48 \mathrm{hr} ;{ }^{1-3}$ however, in some patients with borderline oxygenation, iNO may buy valuable time and may permit improvement in lung function without incurring organ damage from prolonged hypoxemia. Thus, while current data do not support the routine use of iNO, it may be useful as rescue therapy in patients who are severely hypoxemic despite aggressive ventilator strategies.

We conclude that our data demonstrate the ability of iNO to raise $\mathrm{PaO}_{2}$ to a clinically significant extent in patients who are severely hypoxemic. Studies are still required to determine the optimum dose and method of administration.

Acknowledgements

The authors wish to thank the respiratory therapists and intensive care unit staff at St. Joseph's Hospital (Hamilton, Ontario) for their assistance in this trial. Dr. Choi was partially funded by a clinical scholarship (McMaster University) and by the St. Joseph's Hospital Anesthesiologists' Research Fund (Hamilton, Ontario). Competing interests: none. 


\section{References}

1 Michael JR, Barton RG, Saffle JR, et al. Inhaled nitric oxide versus conventional therapy. Effect on oxygenation in ARDS. Am J Resp Crit Care Med 1998; 157: 1372-80.

2 Troncy E, Collet J-P, Shapiro S, et al. Inhaled nitric oxide in acute respiratory distress syndrome. A pilot randomized controlled study. Am J Resp Crit Care Med 1998; 157: 1483-8.

3 Dellinger RP, Zimmerman JL, Taylor $R W$, et al. Effects of inhaled nitric oxide in patients with acute respiratory distress syndrome: results of a randomized phase II trial. Crit Care Med 1998; 26: 15-23.

4 Lundin S, Mang H, Smithies M, Stengvist O, Frostell C, for the European Study Group of Inhaled Nitric Oxide. Inhalation of nitric oxide in acute lung injury: results of a European multicentre study. Intensive Care Med 1999; 25: 911-9.

5 Payen D, Vallet B, and Groupe d'Etude du NO dans l'ARDS. Results of the French prospective multicentric randomized double-blind placebo-controlled trial on inhaled nitric oxide (NO) in ARDS. Intensive Care Med 1999; 25(suppl): S166 (abstract).

6 Willan AR, Pater JL. Carryover and the two-period crossover clinical trial. Biometrics 1986; 42: 593-9.

7 Willan AR Using the maximum test statistic in the two-period crossover clinical trial. Biometrics 1988; 44: 211-8.

8 Ware LB, Matthay $M A$ The acute respiratory distress syndrome. N Engl J Med 2000; 342: 1334-49.

9 Steudel W, Hurford WE, Zapol WM. Inhaled nitric oxide. Basic biology and clinical applications. Anesthesiology 1999; 91: 1090-121.

10 Hart CM. Nitric oxide in adult lung disease. Chest 1999; 115: 1407-17. 